\title{
Od nesigurnosti do nesigurnosti: rad i zaposlenost u kulturnim i kreativnim industrijama
}

\author{
Jaka PRIMORAC \\ Institut za međunarodne odnose, Zagreb, Hrvatska \\ jaka@irmo.hr
}

\begin{abstract}
U članku se analiziraju ključni aspekti rada i zaposlenosti u kulturnim i kreativnim industrijama. Nakon pregleda posebnosti kulturnih i kreativnih industrija od važnosti za razvoj rada i zaposlenosti, problematiziran je i utjecaj informacijskokomunikacijskih tehnologija na njihove promjene pri čemu se ističe i pojava participacijskih modela rada $i$ suradnje. $U$ članku se nadalje iznosi podjela kulturnih radnika/ca, zatim se pruža pregled oblika zaposlenosti u kulturnim i kreativnim industrijama, pri čemu se atipična zaposlenost ističe kao dominantna. Kulturni radnici/e se susreću s nejednakostima koje se očituju u odnosu na rod, klasu, godine te etničku pripadnost. U članku je posebna pozornost posvećena prikazu rodne nejednakosti u radu i zaposlenosti u europskim kulturnim i kreativnim industrijama. Nesigurnosti rada i zaposlenosti u tom su području problematizirane kroz koncept prekarnosti koji je sve dominantniji u eksplikacijama suvremenih radnih promjena. U članku je pokazano da koncept prekarnosti ne može obuhvatiti sve specifičnosti simboličke naravi kulturnih proizvoda i dinamičnosti kulturnih i kreativnih industrija kao institucija simboličke proizvodnje. Zaključni dio pokazuje da su potrebna detaljnija istraživanja koja bi obuhvatila sve aspekte kompleksnosti rada u kulturnim i kreativnim industrijama i koja bi pridonijela boljem ocrtavanju svih njegovih kontradikcija.
\end{abstract}

Ključne riječi: kulturne industrije, kreativne industrije, kreativna ekonomija, rad, zaposlenost, informacijsko-komunikacijske tehnologije, kulturni radnik/ca

\section{Uvod}

U istraživanju kreativne ekonomije rad i zaposlenost sve su donedavno bile zanemarene kategorije (Lovink i Rossiter, 2007). Ponajprije, dosadašnja su istraživanja uglavnom bila usredotočena na mapiranje kulturnih i kreativnih industrija kao najsnažnijeg dijela kreativne ekonomije te na prikaziva- 
nje njihova brzoga ekonomskog rasta najčešce radi izrade javnopolitičkih (policy) dokumenata. ${ }^{1}$ Potom, jedan dio istraživanja kulturnih i kreativnih industrija bio je usredotočen na razvijanje snažnijega terminološkog okvira pri čemu su zapostavljena empirijska istraživanja. Područje kreativne ekonomije predstavlja kompleksan predmet istraživanja najprije zato što simbolički proizvodi nisu poput ostalih proizvoda: posebni su po tome što uz svoju materijalnu imaju i veliku nematerijalnu vrijednost, zbog čega je njihov društveni utjecaj velik. Ujedno, složenosti istraživanja pridonosi i to što u posljednjih nekoliko godina kreativna ekonomija pokazuje vrlo visoke stope rasta i rapidne promjene organizacijskih oblika. Pitanja koja se nužno nameću glase: Što sve točno stoji iza razvoja kreativne ekonomije? Tko su akteri koji su zaslužni za rast toga sektora i kakvi se radni uvjeti skrivaju iza tog rasta? Je li uistinu posao u kreativnoj ekonomiji »posao iz snova« ili je samo »zgodan posao ako ga možeš dobiti«, kako to primjećuje Ross (2007: 17)?

Tek su se posljednjih godina istraživači i istraživačice, kao što su Ross (2008), McRobbie (2002), Pratt (2004), Gill i Pratt (2008), Banks (2007), Hesmondhalgh i Baker (2011) i drugi/e, sustavnije posvetili ovoj problematici. Ovo se naglo zanimanje može pripisati i otrežnjenju nakon prvotne euforije oko pozitivnih primjera koje su iznjedrile javnopolitičke odluke vezane uz kulturne i kreativne industrije (npr. projekt Cool Britanije u Ujedinjenom Kraljevstvu, i Creativ Wirtschaft u Austriji). Nakon toga prvotnog vala oduševljenja na vidjelo su izišle neke od negativnih strana rada u kulturnim i kreativnim industrijama, što je otvorilo raspravu o položaju kulturnih radnika/ca.

Također valja napomenuti da je i u Hrvatskoj analiza tog područja bila zanemarena: uz makroanalize područja rađene za potrebe izvještaja o kulturnoj politici Republike Hrvatske (Cvjetičanin i Katunarić, 1998) i izrade strategije kulturnog razvitka (Katunarić i Cvjetičanin, 2003), postoje samo sporadična i/ili fragmentarna ali ne i sustavna istraživanja ove problematike. Uz analizu zaposlenosti u kreativnim djelatnostima unutar konteksta kulturne industrijalizacije (v. Švob-Đokić, Primorac i Jurlin, 2008), dostupne su i

\footnotetext{
${ }^{1}$ Jedan od ključnih takvih dokumenata mapiranja kreativnih industrija je onaj Ureda za kreativne industrije Odjela za kulturu, medije i sport (DCMS) 1998. godine (DCMS, 1998). Od ostalih dokumenata mogu se istaknuti npr. mapiranje kulturnih industrija u Kolumbiji (Ministerio de Cultura de Colombia i Convenio Andrés Bello, 2003) te kreativnih industrija u Hong Kongu (Hui, 2003). U kontekstu regije jugoistočne Europe mogu se izdvojiti austrijski (Ratzenböck i dr., 2004) te srpski primjer (Jovičić i Mikić, 2006).
} 
pojedinačne studije o društvenom položaju žena-umjetnica (Kodrnja, 2001), upravljačicama u kulturnom sektoru (Adamović, 2011) te društvenom položaju dizajnerica vizualnih komunikacija (Barada, 2012). Ujedno, potrebno je ovdje spomenuti i istraživanja na ovu temu koja su provedena u regiji jugoistočne Europe kao što je studija o položaju kulturnih radnika/ca u kreativnim industrijama jugoistočne Europe (Primorac, 2008), te problematizacija fleksibilizacije kulturnog rada u slovenskom kontekstu (Milohnić, 2005).

Ovim se radom želi dati doprinos osvjeljivanju kompleksnosti područja kulturnog (Banks, 2007) i kreativnog rada (Hesmondhalgh i Baker, 2011) te pružiti novi okvir za daljnje detaljnije sociološko i kulturološko istraživanje ove teme. Nakon prikaza posebnosti kulturnih i kreativnih industrija i utjecaja informacijsko-komunikacijskih tehnologija na promjene rada i zaposlenosti u tom području, ovaj će članak pružiti pregled ključnih problema kulturnog i kreativnog rada, nejednakosti koje proizvode s posebnim naglaskom na njihovu rodnu dimenziju. Prije zaključnog dijela teksta dat će se osvrt i na koncept prekarnosti i njegovu primjenjivost u analizi kulturnog i kreativnog rada.

\section{Posebnosti kulturnih i kreativnih industrija}

Pod kreativnom ekonomijom podrazumijevamo procese proizvodnje, distribucije i potrošnje (nematerijalnih) kreativnih, kulturnih i simboličkih dobara, što uključuje ideje, iskustva, percepcije, slike, softver, medijske sadržaje, dizajn, informacije i usluge. ${ }^{2}$ Kreativna ekonomija također implicira pružanje i pristup uslugama te inovativne načine upravljanja proizvodnim procesima. ${ }^{3}$ Ona nastaje i razvija se temeljem korištenja generičkih informacijskih i komunikacijskih tehnologija (Flew, 2005). Glavnu os kreativne ekonomije na svjetskoj razini čine tzv. kulturne i kreativne industrije koje se - prema posljednjim (predrecesijskim) pokazateljima (KEA, 2006) te podacima UNDP/UNCTAD-a iz 2008. i 2010. godine - ubrajaju u europske i svjetske industrije s najbržom stopom rasta.

$\mathrm{U}$ ovom radu razlikujemo kulturne od kreativnih industrija. $\mathrm{S}$ jedne strane, kad govorimo o kulturnim industrijama, govorimo o onima koje

\footnotetext{
${ }^{2}$ Upravo je Howkins (2003) zaslužan za uvođenje termina »kreativna ekonomija«.

${ }^{3}$ Pregled terminoloških prijepora oko termina »kreativne industrije« i »kreativna ekonomija $\mathrm{s}$ posebnim fokusom na tranzicijski kontekst jugoistočne Europe dostupan je u: Tomić-Koludrović i Petrić, 2005.
} 
obuhvaćaju proizvodnju simboličkih dobara (filmova, glazbe, knjiga, TV programa itd.), njihovu reprodukciju i distribuciju i to ponajprije putem korištenja novih (informacijsko-komunikacijskih) tehnologija (Hesmondhalgh, 2002, 2007). Kulturne industrije odlikuje brzi rast uz kontinuiranu promjenu kulturne proizvodnje i potrošnje, što se odražava na promjenama kulturnih vrijednosti i identiteta. Sam je koncept »kulturne industrije« tijekom godina doživio transformacije - u svom opsegu i sadržaju. Tako se, zahvaljujući znanstvenicima pod vodstvom Bernarda Miégea (rad za UNESCO iz 1979. godine), dogodio prijelaz iz kulturne industrije u jednini u kulturne industrije u množini. Ta terminološka promjena upućuje na sve veću proizvodnju i potrošnju u tome području, zbog razvoja novih medija.

S druge strane, termin »kreativne industrije« prvi je put upotrijebljen 1994. godine u Australiji u dokumentu Creative Nation (Commonwealth Department of Communications and the Arts, 1994). Neki ga autori/ce sagledavaju kao »jasno proširivanje termina 'kulturne industrije' uključivanjem novih tehnologija (multimedije, softvera itd.)« (Ratzenböck i dr., 2004: 10), međutim takvo čisto tehničko objašnjenje nije prikladno jer je riječ o konceptualnom prijelazu od fokusa na kulturu prema prilično širokom i ponekad nejasno definiranom pojmu kreativnosti. Upravo se velika zasluga za promociju samoga koncepta kreativnih industrija pripisuje britanskom utjecaju, tj. laburističkome projektu Cool Britannia i osnutku Ureda za kreativne industrije Odjela za kulturu, medije i sport (DCMS) 1997. godine. Često citirana DCMS-ova (2003) definicija kreativnih industrija određuje ih kao »one industrije koje imaju svoj izvor u individualnoj kreativnosti, sposobnostima i talentu i koje imaju potencijale za stvaranje bogatstva i zapošljavanja kroz generiranje i iskorištavanje intelektualnog vlasništva«. Ako pozornost obratimo na same termine poput »iskorištavanja« i »generiranja« korištene u tekstu dokumenta, uočit ćemo fokus na instrumentalizaciju kulture i kreativnosti u DCMS-ovu pristupu problematici. ${ }^{4}$

Brojna su se istraživanja pretjerano orijentirala na analizu ekonomske strane i komercijalnih koristi od razvitka kulturnih i kreativnih industrija, ${ }^{5}$ a nisu pokušala dohvatiti i/ili kritički promotriti i analizirati njihovu društvenu i kulturnu vrijednost. Upravo su autori/ce poput Lovinka i Rossitera

\footnotetext{
${ }^{4}$ Treba spomenuti američki utjecaj u konceptualizaciji kreativnih industrija kroz rad Richarda E. Cavesa i njegovih sedam ekonomskih principa kreativnih industrija (Caves, 2000). ${ }^{5} \mathrm{Za}$ pregled literature o kulturnim i kreativnim industrijama vidi: O’Connor, 2010.
} 
(2007), ${ }^{6}$ Rossa (2007, 2008), McRobbie (2002), Gill i Pratta (2008), kao i Mayerhofer i Mokre (2007) $)^{7}$ upozorili na neke od problema koji se pojavljuju pri upotrebi koncepta kulturnih te kreativnih industrija. Kritika kulturnih i kreativnih industrija kreće se na nekoliko različitih razina kao što su sljedeće: samom upotrebom koncepta »kreativnih industrija« prihvaćamo neoliberalnu ideologiju instrumentalizacije kulture i kreativnosti (Virno, 2002; Mayerhofer i Mokre, 2007); promocijom kulturnih i/ili kreativnih industrija skriva se prava slika fleksibilnoga/e kulturnog/e radnika/ce u kojoj on/ona radi u neadekvatnim uvjetima (Ross, 2007, 2008; McRobbie, 2002); upotrebom koncepata kulturnih te kreativnih industrija pokušavaju se iznaći jednostavna rješenja za dublje društvene probleme, a zapravo se stvaraju novi (kao što je npr. gentrifikacija), kako ističu Gill i Pratt (2008); preslikavanje koncepata kulturne i/ili kreativne industrije nije prikladno za određene društvene kontekste (Ross, 2007).

Kad razmatramo posebnosti područja kulturnih i kreativnih industrija u kontekstu promjena rada i zaposlenosti, ponajprije bi trebalo napomenuti da su one orijentirane na simboličku proizvodnju, što ih čini područjem visokog rizika. Prema Hesmondhalghu (2002) visoki rizik podrazumijeva da simbolička proizvodnja ima vrlo visoke troškove proizvodnje, a niske troškove (ponovne) izvedbe. Samim time, ona je ovisna o trenutačnoj modi i njezini krajnji proizvodi su polujavna dobra - što stvara potrebu umjetne nestašice (Hesmondhalgh, 2002: 17). Takva visoka rizičnost nije samo relevantna za ulagače/ice, nego je upravo ključna za one koji stvaraju u kulturnim i kreativnim industrijama kada je riječ o prekarnosti njihovih pozicija. Nadalje, McRobbie (2002) nas upozorava kako je tu riječ zapravo o ekonomiji lutrije gdje »pobjednik/ca uzima sve.$^{8}$ No, upravo će Jenkins (2006) i Anderson (2006) pokazati da ova teza više ne stoji: dugoročno gledano, izlazimo iz ekonomije hitova i ulazimo u ekonomiju niša gdje nove tehnologije omogućuju nehitovima da pronađu svoja nišna tržišta (Negroponte, prema Jenkins, 2006: 5). Banks (2007: 11) također podupire ovu

\footnotetext{
${ }^{6}$ Pritom se ponajprije misli na autore/ice okupljene oko MyCreativity liste Instituta za mrežne kulture iz Amsterdama.

${ }^{7}$ Autori/ce okupljeni oko Europskog instituta za progresivne kulturne politike (EIPCP) iz Beča.

${ }^{8} \mathrm{Na}$ isti fenomen upozorava Ruth Towse i naglašava da ga je opisao još i Adam Smith u prvoj knjizi Bogatstva naroda kao the lottery of the law, gdje »vrlo niske naknade idu većini zaposlenih u spomenutim industrijama, dok vrlo visoke naknade idu malom broju, onima koje nazivamo 'zvijezdama'« (Towse, 2003).
} 
tezu podacima kako je većina djelatnika/ca u kreativnoj ekonomiji daleko od zvjezdanog statusa; glavnina ih zapravo radi u anonimnim poduzećima te egzistiraju »od projekta do projekta« na vrlo niskim plaćama. Kako ističu Gill i Pratt (2008: 4), prekarnost je ključna karakteristika rada kulturnih radnika/ca, s tendencijom $\mathrm{k}$ individualizaciji radnih pozicija - prema radnicima/ama s portfeljem, o čemu će biti više riječi u nastavku teksta.

Kao treće, unutar kulturnih i kreativnih industrija posebnost je i u zapošljavanju visokokvalificiranih stručnjaka/inja. Uzmimo za primjer EUROSTAT-ove podatke koji pokazuju kako je »[a]ktivna populacija zaposlenih u području kulture u zemljama EU25 [...] u prosjeku bolje obrazovana nego ukupna radna snaga: podaci za 2002. godinu pokazuju da je $40 \%$ kulturnih djelatnika/ca završilo fakultet, dok je u ukupnoj zaposlenosti $24 \%$ fakultetski obrazovanih« (EUROSTAT, 2004). Slične trendove pokazuju nam i podaci koje nam pruža KEA (2006: 88) gdje je taj odnos 46,8\% naprama $25,7 \%$ u EU25 za 2004. godinu. Noviji podaci EUROSTATA (2011: 64) pokazuju nastavak tog trenda - u svim istraživanim zemljama postotak zaposlenih s fakultetskom naobrazbom veći je nego u ukupnoj zaposlenosti. Kao četvrtu posebnost valja istaknuti da se u kulturnim i kreativnim industrijama traži visok stupanj inovativnosti. Kao posljednja, peta, posebnost ističe se činjenica da su kulturne i kreativne industrije zasnovane na mrežnom pristupu horizontalne prirode, što ponajprije proizlazi iz upotrebe novih informacijskih i komunikacijskih tehnologija. One umnogome utječu na rad i zaposlenost u kreativnoj ekonomiji, tj. u kulturnim i kreativnim industrijama, o čemu će biti više riječi u sljedećem odjeljku.

\section{Kreativna ekonomija i informacijsko-komunikacijske tehnologije}

Kreativna ekonomija, kako tvrdi Castells (2000), nastaje i razvija se u tzv. umreženome društvu u kojem su inovacije u informatičkim i komunikacijskim tehnologijama uz procese digitalizacije otvorile niz pitanja vezanih uz shvaćanje novih načina distribucije, potrošnje i proizvodnje kulturnih dobara i usluga. Tako su se, tehnološkom konvergencijom, kroz stapanje (tele)komunikacija i informacijskih tehnologija, stvorile nove mogućnosti za kulturnu interakciju. No, do konvergencije ne dolazi samo na tehnološkoj razini: ona implicira stapanje višestrukih medijskih sustava, što omogućuje da kroz njih različiti medijski sadržaji cirkuliraju i supostoje (Jenkins, 2006). Ove mogućnosti dopuštaju brz protok simbola preko virtualnih i 
fizičkih granica koji za posljedicu (između ostaloga) imaju procese hibridizacije kulturnih oblika i (lokalnu) kulturnu promjenu. Tako se razvijaju novi oblici interkulturne komunikacije, što povećava raznolikost u realnoj, ali i u digitalnoj domeni. Sve ove kulturne promjene nastaju tako velikom brzinom da je teško procijeniti implikacije novonastalih uvjeta uključujući pitanja privatnosti i slobode govora.

Utjecaj novih tehnologija u kreativnoj ekonomiji podrazumijeva i problem pristupa koji implicira i pitanja prava intelektualnog vlasništva od kojih su najčešća autorsko pravo, patenti, zaštitni znakovi te dizajn. U novonastalim uvjetima, kad simbolička proizvodnja postaje dominantnim oblikom proizvodnje, u kojem je taj krajnji proizvod fizički neopipljiv (ili je eventualno zabilježen na nosaču, čija materijalna vrijednost sama po sebi nije velika), pitanja vlasništva nad tim istim sadržajem postaju prevladavajuća, pogotovo kada je riječ o velikom profitu te kad su u igru uključene multinacionalne korporacije. S druge strane, pitanja javne domene, i dostupnosti (kulturne) razmjene su ključna dimenzija tih problema. U svjetlu rasprava o pretjeranoj reguliranosti digitalne sfere, valja se zapitati hoće li znanje, informacije i kreativni input postati dostupnima samo onima koji će si ih moći priuštiti ili će biti dostupni svima. Nadalje, kako će autori/ ce biti nagrađeni za rad u takvim uvjetima? Kako razriješiti ove dvojbe u fluidnim uvjetima proizišlim uslijed procesa digitalizacije, postaje jedan od ključnih problema.

Inovacije informacijsko-komunikacijskih tehnologija, a potom i implikacije koje donosi digitalizacija, zakonodavni okvir ne može uvijek primjereno popratiti - pa tako trenutačni zakoni koji se tiču sadržaja u digitalnom obliku i prijenosa tih istih sadržaja zaostaju za njihovim razvojem. ${ }^{9}$ Nove načine prikazivanja i distribucije sadržaja, na primjer peer-to-peer (p2p) i Bit Torrent, različite web-stranice i alate za društveno umreživanje (npr. MySpace, Facebook, Last.fm), trenutačna legislativa ne može slijediti. Web 2.0, a odnedavno i Web 3.0 okruženja su koja su zasnovana na participaciji sudionika/ca te sadržaju i uslugama koje stvaraju korisnici/e. Upravo je taj promijenjeni kontekst potrebno promotriti i kroz promjene zakonske regulative kako bi ona odgovarala novim uvjetima. Softver otvorenoga koda (Open Source Software), »opće javne licence« (General Public Licence) i Creative Commons licence zasnovane su na ideji otvorenosti i slobodne

\footnotetext{
${ }_{9}$ Pokušaj kompanija da ostvare regulaciju kakva njima odgovara vidljiva je u pokušaju primjene SOPA-e, PIPA-e te ACTA-e početkom 2012.godine.
} 
razmjene, a neki su od alternativnih odgovora na prethodno navedene nove uvjete. Uspjeh projekata otvorenoga koda (kao što je Linux) i zajedničkog rada (kao što je Wikipedia) pokazuju koliko daleko takav pristup može dovesti u novostvorenim uvjetima. Još prije nekoliko godina ti su se projekti činili utopijskima, no danas se natječu sa svojim komercijalnim pandanima, pa su tako informacijske i komunikacijske tehnologije utjecale i na boom kreativne ekonomije na dotad »neočekivanim« mjestima. Tako je, primjerice, nigerijska filmska produkcija jedna od svjetskih filmskih produkcija koje se najbrže razvijaju; tzv. Nollywood proizvodi više od 1200 filmova godišnje i to ne samo za lokalnu, nego i za međunarodnu distribuciju (IDRC, 2007: 19), a filmska industrija u Nigeriji slijedi, nakon poljoprivrede, kao industrija koji zapošljava najveći broj ljudi. Upravo je za ovakav tip industrije ključan faktor razvoja bila digitalna tehnologija koja je omogućila brzu i jednostavnu proizvodnju i distribuciju te veću fleksibilnost u radu kao i snižavanju troškova na svim razinama.

Treba napomenuti da za razvoj kreativne ekonomije nije bitna samo komercijalna razmjena, nego su postali važni i nekomercijalni oblici razmjene. Novi nevlasnički (non-proprietory) projekti, koji su zasnovani na suradnji velikog broja ljudi, utječu na razvoj kulture i kreativnosti, kao što je to Benkler primijetio: »Niz promjena u tehnologijama, ekonomskoj organizaciji i društvenim navadama proizvodnje u ovom području stvorili su nove prilike za načine stvaranja i razmjene informacija, znanja i kulture. Ove promjene povećale su ulogu netržišne i nevlasničke proizvodnje, kako kod pojedinaca tako i kod zajedničkih pokušaja unutar širokog spektra slabije ili čvršće povezanih suradnji« (2006: 2). Primjer takvoga novog modusa rada $\mathrm{u}$ području kreativne ekonomije sve su više procesi crowdsourcinga ${ }^{10}$ pa se $\mathrm{u}$ tom kontekstu govori i o nastanku participacijske ekonomije (Lovink $\mathrm{i}$ Rossiter, 2007). Upravo nas ova forma rada upućuje na pojavu novog fenomena - pojavu zajedničkog rada za opću dobrobit, kakav se pojavljuje kod mreža inženjera/ki i aktivista/ica Slobodnog softvera / Softvera otvorenog koda (Free/Open Source Software - FOSS) koji motivaciju pronalaze u samom postignuću i priznanju ostalih članova/ica FOSS zajednice. U slučaju

\footnotetext{
${ }_{10}$ Jeff Howe prvi je upotrijebio ovaj pojam u članku »Rast crowdsourcinga« u časopisu Wired u svibnju 2006. godine, iako je taj termin i prije upotrebljavan u tumačenjima novih modela biznisa kao što su iStockphoto i sl. Crowdsourcing je davanje zadataka (najčešće na osnovi javnoga poziva) nekoj neodređenoj skupini ljudi ili zajednici, radi bržeg i efikasnijeg rješavanja problema. Rješenje problema ostaje u rukama naručitelja/ice, koji/a ponekad nudi naknadu za obavljen zadatak, a nekada je slava jedina nagrada.
} 
FOSS-a riječ je o potpunom prožimanju radnog vremena i vremena dokolice - nekadašnja stroga odvojenost ovih dviju sfera je nestala. No, kad korporacije preuzmu modele nevlasničke (non-proprietory) razmjene, tada se postavlja pitanje koliko one iskorištavaju rad za opće dobro: »Zavedene mogućnostima korištenja neplaćenih stručnjaka/inja, tehnomultinacionalke sve više prihvaćaju softver otvorenog koda kakav je Linux. Tako pojačavaju opću zabrinutost da će princip slobodnog softvera za sve ljude na kraju značiti besplatan rad za korporacije« (Ross, 2007: 20).

Gledano iz perspektive stvaratelja/ica, fluidnost proizvodnje i razmjene u digitalnoj areni donosi nova stvaralačka i radnopravna pitanja na svakodnevnoj razini, a primjena trenutačnih pravnih okvira na digitalnu sferu stvara paradoksalne situacije. ${ }^{11}$ Interesi autora/ica, korisnika/ca i (multimedijalnih) kompanija razlikuju se ali se i suprotstavljaju: autor/ica želi biti nagrađen/a za svoj rad, cilj korisnika/ca jest steći što lakši pristup sadržaju, a kompanije žele ostvariti što veći profit. Razmjenski potencijali novih tehnologija mogu pridonijeti razvijanju alternativnih kulturnih modela. Coleman (2005) naglašava da su prava intelektualnog vlasništva u svojoj srži romantičarska jer se zasnivaju na ideji »stvaratelja/ice genijalca/ke« koji/a ulazi ab ovo u stvaralački proces. Upravo su zato uvidi u istraživanja o hakerima/cama relevantni i za istraživanja o radu u kulturnim i kreativnim industrijama jer hakeri/ce shvaćaju kreativnost kao trenutak mudre intervencije unutar određenog polja ograničenja. Hakere/ice ovdje shvaćamo šire od samoga informatičkog sektora te ih zato ne promatramo kao unificiranu skupinu. Upravo kroz svoj rad i djelovanje hakeri/ce pokazuju da su alternative već postojećim sustavima moguće te da mogu proizići iz samog sustava. U tome Coleman vidi njihovu ključnu vrijednost koju često zanemaruju teoretičari/ke koji naglašavaju potrebu za jasnim prekidima, tj. rezovima s dominantnim sustavima. ${ }^{12}$

Treba nadodati da se, bez obzira na razvijanje inovativnih oblika organizacijske logike potaknute novim tehnološkim dostignućima ne smijemo previše oslanjati samo na mrežnu komunikaciju kao ključni eksplikacijski

\footnotetext{
${ }^{11}$ Na primjer, slučaj studenta Jessea Jordana koji je modificirao jednu intranetsku tražilicu; kako je modificirana tražilica davala linkove na piratske materijale dostupne online, Jesse je proglašen piratom, a Američko udruženje diskografske industrije (Recording Industry Association of America /RIAA/) tužilo ga je za kršenje autorskih prava u vrijednosti od 15.000.000,00 američkih dolara, koje on de facto nije počinio (Lessig, 2004: 48-52). Nažalost, slični novi primjeri pojavljuju se svakog mjeseca.

${ }^{12}$ Coleman (2005) pritom misli na Haraway, Hardta, Negrija i Gallowaya.
} 
faktor razvoja kreativne ekonomije. Tehnologija nije jedini čimbenik koji odlučuje o razvoju određenoga (informacijskoga) društva kao što je to već pokazao Castells (2000: 241) na primjeru Japana i Amerike gdje je upozorio na to da su širenje informacijske zaposlenosti odnosno zaposlenosti u informacijskom sektoru i razvoj informacijskoga društva dva odvojena procesa. Tako kad govorimo o razvoju kreativne ekonomije, moramo istaknuti da nije dovoljan samo razvoj informacijsko-komunikacijskih tehnologija, nego i unapređenje kulturne, obrazovne, poslovne i prostorne infrastrukture. Prostorna je dimenzija ipak još uvijek važna kao i neposredna komunikacija među ljudima koja, osim one svrsishodne odnosno namjerne komunikacije, sadržava i onu usputnu, nenamjernu kao i emotivnu komponentu. Jasno je da jedan oblik komunikacije ne zamjenjuje drugi, nego se oni nadopunjuju i razvijaju paralelno. No, bez obzira na to koliko je za razvoj kreativne ekonomije važno djelovanje »u mreži«, za nju je bitna i ta prostorna dimenzija, pri čemu se pod njom ponajprije misli na područje gradova. Tako su istraživanja na području kulturne geografije, kao što je pitanje stvaranja »klastera« i urbane regeneracije gradova putem kulturnih projekata, pridonijela boljem razumijevanju važnosti prostorne dimenzije za kreativnu ekonomiju (Radcliffe, 2006). Argumentaciju važnosti gradova za razvoj kreativne ekonomije, između ostalih, dali su i Scott (1999), Castells (2000), Florida $(2002,2007)$ te Landry (2000) koji ističu kako gradovi sadržavaju koncentraciju znanja, tehnološke i ostalih razina inovativnosti, kao i kulturne infrastrukture, financijskih institucija i ljudstva čije je međudjelovanje nužno za razvoj kreativne ekonomije.

\section{Kulturni radnici/e, oblici zaposlenosti i nejednakost}

U razdoblju od 2000. do 2005. promet u proizvodima i uslugama kreativnih industrija na svjetskoj razini rastao je po godišnjoj stopi od 8,7\%, kao što to pokazuju podaci UNDP/UNCTAD-a (2008: 24). Pritom nije zanemariv doprinos kulturnih i kreativnih industrija u zaposlenosti - on se kreće otprilike $2-8 \%$ radne snage, što doduše ovisi o samoj definiciji polja. Ovdje na trenutak valja zastati i istaknuti kako upravo zahvaljujući spomenutoj »terminološkoj zbrci« može doći do krivih zaključaka koji na javnopolitičkoj razini mogu dovesti do negativnih rezultata po npr. financiranje kulturnog sektora općenito, kad se argumenti o visokom ekonomskom rastu žele iskoristiti za smanjivanje udjela financiranja iz javnih fondova. Mora se napomenuti i da rad/zaposlenost u ovome području ima specifične karakteristike 
jer zahtjeva visok stupanj obrazovanja i kvalifikacija kao i veliku radnu intenzivnost, kako je istaknuto u izvještaju UNDP/UNCTAD-a (2008: 25). No, također valja uzeti u obzir da je recesija djelovala i na ovo područje kako pokazuju noviji izvještaji UNDP/UNCTAD-a (2010: 23), iako je još uvijek teško dati egzaktne podatke o njezinu sveukupnom utjecaju.

Za početak je kao ilustraciju podjele radnika/ca uzeta Hesmondhalghova klasifikacija analize organizacije rada u kulturnim industrijama koja razlikuje četiri temeljne skupine djelatnika/ca: ključno kreativno osoblje, tehničke zanatske djelatnike/ce, kreativne menadžere/ice te vlasnike/ce i rukovoditelje/ice (Hesmondhalgh, 2002: 52-53), pri čemu je rad u (autonomnim) projektnim timovima od ključne važnosti za kulturne i kreativne industrije. U tom smislu, kad govorimo o zaposlenosti u kulturnim i kreativnim industrijama, možemo govoriti o trima različitim situacijama (prema KEA, 2006: 75), pri čemu u podjelu uključujemo i »kreativna« i »nekreativna« zanimanja. Prva se situacija odnosi na kulturne radnike/ce koji rade u kulturnim $i$ kreativnim industrijama (npr. spisatelj/ica u izdavačkoj industriji), druga se odnosi na kulturne radnike/ce koji rade izvan kulturnih $i$ kreativnih industrija (npr. dizajner/ica u automobilskoj industriji), dok se treća odnosi na radnike/ce ostalih profesija koji rade u kulturnim i kreativnim industrijama (npr. tajnik/ca u glazbenoprodukcijskoj kući). Na taj se način može primijetiti i velika razlika između radnika/ca u kulturnim i kreativnim industrijama, npr. između onih koji proizvode sadržaje te onih koji »menadžeriraju« proizvodnju tih sadržaja, što je već spomenuta podjela na »kreativna« i »nekreativna« zanimanja (Throsby, 2003: 177). No, te razlike još dodatno usložnjavaju i diverzifikacije između samih djelatnosti, primjerice razlike između (uvjeta i načina) rada u arhitekturi ili u filmskoj industriji.

U ovom bi kontekstu bilo nužno istaknuti i poseban položaj umjetnika/ca kao specifične kategorije kulturnih radnika/ca čiji rad obilježavaju slične karakteristike, a koji također bivaju zaposleni u kulturnim i kreativnim industrijama. Towse nudi sljedeće objašnjenje položaja umjetnika/ ca: »umjetnici/e najčešće rade nekoliko poslova; dominiraju samostalni i freelance djelatnici/e, rad je neredovit, ugovori su kratkoročni, zaštita zaposlenja je mala; budućnost karijere je nesigurna; plaće su nejednake; umjetnici/e su mlađi od ostalih djelatnika/ca; i radna snaga je u porastu« (Towse, prema Hesmondhalgh, 2007: 61). Status umjetnika/ca na taj je način izrazito prekaran, zbog čega je u određenim zemljama reguliran poseb- 
nim javnopolitičkim odredbama (npr. reguliranje statusa samostalnih umjetnika/ca i sl.) kojima se nastoji smanjiti razina nesigurnosti. No, kao što to navodi Throsby (1992: 201), »analiza njihovih odluka o ponudi rada, a time i njihovih prihoda, zahtijeva specifičan model koji se ne bi mogao koristiti za druge djelatnike/ce«.

U studijama o kulturnim i kreativnim industrijama oblik rada i zaposlenosti najčešće je definiran kao atipični oblik zaposlenosti odnosno, kao nestandardni oblik rada i zaposlenosti. Kako je istaknuto u studiji o zaposlenosti u kulturnom sektoru Europske unije u doba digitalizacije, »atipični oblici zaposlenosti« u kreativnim industrijama su »fleksibilnost, mobilnost, rad po projektima, kratkoročni ugovori, honorarni rad, volonterske i nisko plaćene aktivnosti, pseudozapošljavanje, pseudosamozapošljavanje/freelancing« (MKW, 2001: 25). Upravo su to sve oblici tzv. nestandardnog rada/ zaposlenosti kako ga je ocrtao Edgell (2006), ali i oblici neplaćenog rada te podzapošljavanja.

Zanimljivo je što broj »atipičnih zaposlenja« svakoga dana sve više raste i samim time postaje sve »tipičniji« kao oblik zapošljavanja općenito. Kako pokazuju indikatori u nastavku teksta, ovaj trend je najizraženiji u sektoru za kulturu. U analizi zaposlenosti kulturnih radnika/ca u Europi, koju nam pruža EUROSTAT, pokazuje se da je zaposlenje kulturnih radnika/ca sve nesigurnije, a broj je djelatnika/ca koji imaju »atipični oblik zaposlenja《 sve veći: »18\% kulturnih radnika/ca radilo je na određeno radno vrijeme u usporedbi s 12\% ukupne radne snage država EU25 u 2002. godini; $25 \%$ kulturnih radnika/ca bilo je honorarno zaposleno u usporedbi sa $17 \%$ EU radne snage i $9 \%$ kulturnih radnika/ca imalo je više od jednog zaposlenja, tri puta više od ukupno zaposlenih (3\%)« (EUROSTAT, 2004). Slične nam podatke daje i KEA-ina studija: »dok u ukupnoj zaposlenosti ima 17,6\% honorarno zaposlenih, u kulturi je to svaki četvrti/a« (2006: 95). Noviji podaci EUROSTAT-a upućuju na teze o daljnjem širenju prekarnosti jer je postotak honorarno zaposlenih u ukupnoj zaposlenosti narastao (na 19\%), dok je u kulturi to još uvijek svaki četvrti/a (2011: 64). Postotak nezavisnih djelatnika/ca više je nego dvostruko veći u kulturnome sektoru nego u ukupnoj zaposlenosti, dok je broj honorarno zaposlenih veći u kulturnom sektoru nego u ukupnoj zaposlenosti (KEA, 2006: 91-95). Ista studija također ističe kako sve veći broj zaposlenih u kulturnome sektoru ima nekoliko poslova istovremeno, za razliku od ukupnog broja zaposlenih. Noviji podaci EUROSTAT-a (2011: 64-65) podupiru ove tvrdnje - rad na 
nekoliko poslova istovremeno češći je u kulturnom sektoru nego u ukupnoj zaposlenosti: $6 \%$ prema 4\%. Dakle, može se reći da je u kulturnome $i$ kreativnome sektoru na europskoj razini veći broj nestandardno zaposlenih nego li u ukupnoj zaposlenosti, tj. da je veći broj honorarno zaposlenih, zaposlenih s nepunim radnim vremenom, povremeno zaposlenih te onih koji su istodobno zaposleni na nekoliko poslova tj. koji imaju dodatne poslove.

Specifičnosti rada i zaposlenosti u kulturnim i kreativnim industrijama prouzročene su time što je u njihovu slučaju riječ o komunikaciji iskustava kroz simboličku proizvodnju (Hesmondhalgh i Baker, 2011). One proizlaze iz kontradikcija između zahtjeva umjetničke kreativnosti s jedne $\mathrm{i}$ »diktata « tržišta s druge strane, a upisane su u određene organizacijske kontekste tih industrija. Treba napomenuti da kulturne i kreativne industrije odražavaju i postojeće nejednakosti i nepravde (npr. na klasnoj, rodnoj i etničkoj osnovi) koje su prisutne u suvremenim kapitalističkim društvima, te da postoje velike nejednakosti i u samom pristupu kulturnim i kreativnim industrijama (Hesmondhalgh, 2002: 5-6) pa se tako postavlja pitanja tko su radnici/e koji rade u takvim uvjetima, tj. tko najlakše podnosi takav način rada $i$ komu on odgovara. U tom je smislu zanimljiv opis medijske teoretičarke Marie-Luise Angerer koja za radnika/cu u kreativnoj ekonomiji kaže da je to »najčešce osoba između 25 i 30 godina, vrlo vješta, fleksibilna, psihološki čvrsta, nezavisna, nevjenčana, nije vezana uz neku određenu lokaciju, i spremna je prihvatiti bilo kakvu priliku iz područja umjetnosti, glazbe ili medija« (Angerer, prema MKW, 2001: 16). Imajući na umu negativne ali i pozitivne karakteristike ovoga tipa rada, mora se primijetiti da je ovo područje privlačno mlađima ponajprije zbog svoje dinamičnosti. Rad u kreativnoj ekonomiji podrazumijeva velika ulaganja na samom početku karijere, kad se u mnogo situacija od radnika/ca očekuje i volonterski rad: »Još jedna značajka usiljene mladolikosti jest očekivanje da se radi besplatno«, kritizira tako McRobbie (2002). Tip rada u kreativnoj ekonomiji »podrazumijeva« potpunu predanost poslu, identifikaciju s poslom kao takvim: »Poticaj, štoviše uvjeravanje pojedinca da pronađe smisao života u radu, da se identificira s radom, novi je normativni način osiguravanja 'civilizacije kroz identifikaciju' « (Rose, prema McRobbie, 2002). Ross (2008: 34) također navodi da višestruka etnografska istraživanja pokazuju kako zadovoljstvo radom u kreativnim industrijama u konačnici biva skupo plaćeno i to dugim radnim satima, ustupcima u cijeni radi odgovarajućega estetskog priznanja, samoeksploatacijom poradi autonomije te zamjenjivošću u zamjenu 
za fleksibilnost. U tom bi smislu trebalo razvijati okvire za zaštitu takvih »nestandardnih « oblika rada kako bi postali jednakovrijedni standardnim oblicima zaposlenosti. Na tom tragu su i Hesmondhalgh i Baker (2011: 75), koji naglašavaju prepreke za nove oblike sindikalnog udruživanja (i/ili sličnih modela umreživanja i stvaranja kolektivne zaštite radnika/ca) uslijed negativnih posljedica procesa individualizacije koji su istaknuti u području kulturnih i kreativnih industrija.

\section{Rodna dimenzija rada u kulturnim i kreativnim industrijama}

Iz prethodnog je odjeljka vidljivo da se pojavljuju nejednakosti u odnosu na pristup radu i zapošljavanju u ovom sektoru - Hesmondhalgh i Baker (2011) koji ističu kako malo djelatnika/ca uspijeva izgraditi i održati karijeru u kulturnim industrijama jer narav kreativnog rada zahtijeva dugotrajna vremenska i financijska ulaganja u vještine i ekspertizu, a podrazumijeva i dulja razdoblja neplaćenog rada te se time stvaraju nejednakosti na klasnoj osnovi. Isti autori naglašavaju da se pojavljuju i razlike u odustajanju od karijere u kulturnim industrijama kako zbog godina, tako i zbog rodne ali i etničke dimenzije. Ujedno, McRobbie (2002) sugerira da su žene unutar tog sektora u lošijem položaju od muškaraca, pri čemu se ne smije zaboraviti naglasiti i etničku dimenziju nejednakosti (Hesmondhalgh i Baker, 2011). Pritom valja istaknuti da nove informacijske i komunikacijske tehnologije, kao jedan od ključnih pokretača razvoja kreativne ekonomije, još uvijek repliciraju hijerarhije ekonomske moći iz »stvarnog svijeta«. Dakle, nisu se ostvarila očekivanja da će one imati emancipatorsku moć u rodnome smislu pa se tako govori o »rodnome digitalnom jazu « (gender digital divide), koji se također treba premostiti. Kako ističe Sassen, »[n]a taj način bilo bi možda naivno precijeniti emancipatorsku moć kibersvijeta u smislu njegova kapaciteta neutraliziranja rodnih razlika« (Sassen, 2002: 377). Žene se još uvijek ne koriste informacijskim i komunikacijskim tehnologijama u jednakom omjeru kao muškarci. Još uvijek postoji velika razlika u visokom obrazovanju u informacijskim i komunikacijskim tehnologijama između mladića i djevojaka. Točnije, ako gledamo podatke na europskoj razini, govorimo o $87 \%$ mladića prema $13 \%$ djevojaka u visokom obrazovanju za informacijsko-komunikacijske tehnologije, prema podacima eEurope + koje navodi UNDP/UNIFEM (2004: 13).

Kad je riječ o zaposlenosti u kulturi i kulturnim i kreativnim industrijama, podaci pokazuju da je, na europskoj razini, manje žena zaposleno u 
ovome sektoru - žene čine 45\% zaposlenih u području kulture. Zaposlenost žena u kulturnome sektoru u prosjeku ne odstupa mnogo od postotka zaposlenosti žena u ukupnoj zaposlenosti na europskoj razini, kako je prikazano u studiji KEA (2006: 83-84). No, prema podacima studije ERICartsa njihova zaposlenost po određenim kulturnim područjima varira iz područja u područje pa tako npr. u području filma i videa ona iznosi $40 \%$, dok žene zaposlene u izdavaštvu čine $48 \%$ od ukupnog broja zaposlenih. U nekim je, pak, područjima situacija upravo suprotna, pa je tako u području umjetnosti zaposleno više žena nego muškaraca - 52\% (KEA, 2006: 84). Prema podacima istog istraživanja, žene se još uvijek susreću s preprekama u napredovanju u većim kompanijama koje uključuju tzv. »nevidljive zidove« i »muške klubove«. Zbog tih razloga, jedan dio žena, ako je u mogućnosti, okreće se osnivanju manjih kompanija, u čemu se oslanjaju na nove informacijsko-komunikacijske tehnologije. Podaci ERICartsa (2005) pokazuju da je u području kulture na europskoj razini još uvijek prisutna nejednakost u ovom sektoru, dok se u nekim područjima pojavljuje feminizacija koja za sobom povlači i niži status i niže plaće. Podaci iz drugih izvora također pokazuju trend dominacije muškaraca u sektoru kulturnih i kreativnih industrija: »Vjerojatnije je da će muškarci prije nego li žene moći raditi u kreativnim industrijama na održiv način. Oni su ili vrlo mladi (21-25 godina) ili u zrelim godinama (više od 55 godina) i žive u zajedničkom kućanstvu s partnerom/icom« (Reidl, Schiffbänker i Eichmann, 2006: 12).

$\mathrm{O}$ daljnjoj rodnoj neravnopravnosti u području kreativne ekonomije u Europi podatke iznose njemački istraživači/ce: »Sljedeći važan zaključak analiziranih izvještaja je da je položaj umjetnica još gori od položaja njihovih muških kolega (Angerer i dr., Almhofer i dr., Cliche i dr. 2000, Swanson/Wise, Schulz i Krings). Općenito govoreći, postoji primjetna razlika u prihodima između muškaraca i žena u svim sektorima, pri čemu ni kulturni sektor nije iznimka. U gotovo svim europskim zemljama [...] ova se razlika nije smanjila nego se čak povećala. Ovo ne možemo pripisati manjoj aktivnosti žena, nego činjenici da je više žena zaposleno honorarno. No, žene više rade pod atipičnim uvjetima zaposlenja nego muškarci. Moglo bi se čak reći da je porast atipičnih radnih uvjeta, u biti, produžetak tipičnih uvjeta rada žena na sve one koji su zaposleni ili traže posao (Fink, Kocka/ Offe, Neyer)« (MKW, 2001: 25).

$\mathrm{S}$ druge strane, treba istaknuti kako je u kreativnoj ekonomiji sve veći broj i povremeno zaposlenih. Podaci KEA-e (2006: 93) za EU25 
pokazuju da je u kulturnom sektoru povremeno zaposlenih $17 \%$ u usporedbi s 13,3\% u ukupnoj zaposlenosti. Oblici povremenog rada posebno su zanimljivi kad se promatraju iz rodne perspektive jer, prema pokazateljima, žene čine većinu povremeno zaposlenih u ukupnoj ekonomiji. Kako su to pokazala istraživanja iz Velike Britanije, »velik dio te skupine tvorili su povremeno zaposleni radnici ( $85 \%$ od kojih su bile žene), koji su činili 23,9\% zaposlenog stanovništva« (Castells, 2000: 294). Doduše, prema prethodno spomenutim podacima, nemamo uvid u to koliki se broj povremeno zaposlenih odnosi na kreativnu ekonomiju, ali nam može poslužiti kao važan pokazatelj trenda. Ujedno valja naglasiti da je u mnogim analizama zapošljavanja rodna dimenzija bila zapostavljena: metodološke analize rada te zaposlenosti u dohotku domaćinstva najčešće se zasnivaju na prinosima od rada "glavnog hranitelja - muškarca« te se tako i u klasnim analizama zapostavljaju žene ili ih se briše (Beck, 2001: 155). U tome smislu neplaćeni rad - kućanski poslovi (kao i volonterski poslovi) koje u većini obavljaju žene - nije uključen u analizu rada pa stoga ne možemo u potpunosti procijeniti koliki je ekonomski doprinos žena u društvu.

\section{Nesigurnost rada u kulturnim i kreativnim industrijama}

Koliko nas klizno radno vrijeme, dijeljenje posla ili rad od kuće »oslobađaju« od rada, a koliko nam zapravo prožimaju cjelokupno životno vrijeme? Za razliku od teoretičara poput Rifkina koji su bombastično govorili o kraju rada (1995), može se reći da rad ne nestaje nego se iz temelja mijenja. Tako se nastavljaju Castellsove teze u kojima on npr. pobija postavke o stvaranju društva bez posla, koje zastupa više autora, ${ }^{13}$ konstatirajući da njihove analize nisu dovoljne te pokazuje kako su se rad i zaposlenost doista promijenili. Ono što nestaje jest tradicionalan oblik rada na kakav smo dosad navikli, kao što je stalna zaposlenost, dok se pojavljuju novi oblici rada, novi oblici zaposlenosti. Pritom bi valjalo naglasiti da je ključna karakteristika tih novih oblika rada to da su oni nestalni, što je izravna posljedica fleksibiliziranja rada o čijim je učincima na karakter osobe među prvima govorio Sennett (1998) kroz prikaz drastično različitih radnih putanja koje su se dogodile unutar jedne generacije. Dakle, standardni oblici rada/zaposlenosti bivaju zamijenjeni nestandardnima, tako da kad govorimo

\footnotetext{
${ }^{13}$ Riječ je o sljedećim autorima: King, 1991; Rifkin, 1995; Aznar, 1993; Aronowitz i Di Fazio, 1994 (prema Castells, 2000: 284).
} 
o »nestajanju« u kontekstu rada, možemo samo reći da nestaje radno mjesto $u$ doslovnom smislu, ali ne i rad sam.

U tom se kontekstu postavlja pitanje koliko nam rada i koliko nam dokolice preostaje. Je li riječ u tom slučaju o prividu fleksibilizacije radnog vremena, koje je fleksibilno utoliko što neprekidno moramo biti spremni na rad? Ako su na taj način rad i dokolica »na čekanju«, koliko »dobrovoljno« postajemo robovi rada? Upravo nesigurni ugovorni uvjeti pod kojima se rad odvija postavljaju radnike/ce u takvu poziciju da ne mogu odbiti »raditi na zahtjev«, jer će se možda već sutra naći netko drugi tko će pristati na takve (nepovoljne) uvjete, pogotovo u kulturnim i kreativnim industrijama gdje je velik broj zainteresiranih za ulazak u sektor. Karijera postaje ne samo posao već sveukupni način života u kojem se sve više gube granice između rada, života i igre, a razlika između stvaralaštva tj. proizvodnje i potrošnje nije uvijek jasna. Transformirani rad uslijed kojeg je radnik/ca stalno »na čekanju« te uvijek dostupan, čime se prožima rad i slobodno vrijeme, pretpostavlja sve veće i nove zahtjeve za promjene temeljnih radnih prava djelatnika/ca. S druge strane, uz sveopću fleksibilizaciju sami radnici/e i njihova publika se sve više približavaju jedni drugima, a u nekim se slučajevima radi i o zamjeni uloga pa tako i publika postaje (su)stvarateljica.

Fleksibiliziranje rada za negativnu posljedicu ima ranjivost radnika/ca s obzirom na brze promjene u fleksibilnoj radnoj mreži, što utječe na opću nesigurnost sveukupne pozicije radnika/ca. Virno (2004: 55-58) tvrdi da su upravo kulturni radnici/e i umjetnici/e bili među prvima koji su se »odrekli« svojih radnih prava. Virno također smatra da način umjetničkoga rada kroz povijest navodi na zaključak da upravo iz th njihovih poteza izvire koncept fleksibilnosti radnih procesa. »U kulturnoj industriji, čak i u onoj arhaičnoj koju su proučavali Benjamin i Adorno, može se zamijetiti najava načina proizvodnje koji će se kasnije, s postfordizmom, generalizirati i uzdići u rang kanona« (Virno, 2004: 56). Riječ je o nestandardnome tipu rada/zaposlenosti u smislu ugovora, lokacije, radnoga vremena, ali i raspodjeli rada prema rodnom ključu. No, ne može se reći da je njihov specifični način rada odricanje od radnih prava, nego da označava drukčiju narav umjetničkoga rada i rada kulturnih djelatnika/ca, i posljedično neadekvatne (javnopolitičke) okvire za zaštitu takvih »nestandardnih « oblika rada i neprihvaćanje nestandardnih oblika rada/zaposlenosti kao jednakovrijednih standardnim oblicima zaposlenosti te potrebu za iznalaženjem novih načina zaštite i sigurnosti. Problematičnim se čini da se »kreativnost« nekog posla 
koristi kao izlika za smanjivanje (stečenih) radnih prava, kao i imputiranje da je fleksibilnost u radu u kulturnim i kreativnim industrijama inherentno pozitivna.

Upravo u kontekstu kreativne ekonomije procesi fleksibilizacije i individualizacije vode tomu da kulturni radnici/e postaju samostalne radne jedinice (Beck, 2001). ${ }^{14}$ Iako se uvijek ističu prednosti takvih »samostalnih radnih jedinica« koje mogu fleksibilno surađivati prema individualnom izboru i potrebi s vrlo velikim brojem odabranih suradnika/ca, kao negativna strana pojavljuje se sveopća nesigurnost takve pozicije, tj. govori se o prekarnosti. »Tim se terminom, koji u širem smislu označava aktualne životne uvjete, a u užem radne okolnosti i taktike preživljavanja, pokušava obuhvatiti i objasniti kompleksne promjene pozicioniranosti radnika i njihovog rada, okolnosti pod kojima su makroekonomske, proizvodnoprodukcijske transformacije, dovele do situacije trajne radne i životne nesigurnosti sve većeg dijela populacije i porast strukturalne nezaposlenosti na mikrorazinama života« (Hromadžić, 2008: 36). ${ }^{15}$ Prekarnost tako počinje biti prevladavajuća za sve oblike rada u suvremenome kapitalističkom društvu, ona više nije iznimka od pravila.

No, trebalo bi istaknuti da je prekarnost bila norma puno dulje u povijesti kapitalizma: radnici/e i sindikati su se relativno »nedavno« izborili za radnička prava, i to samo u zemljama razvijenoga industrijskoga kapitalizma, što nije dugo trajalo. Dakle, kako ističu Neilson i Rossiter (2008: 54), ako gledamo kapitalizam u široj povijesnoj perspektivi, tada možemo reći da je prekarnost norma, a da je fordistička organizacija rada zapravo aberacija ili iznimka. Međutim, model prekarnosti je u suvremenome kapitalističkom društvu infiltriran iz modela nižekvalificiranih radnih pozicija u ove višekvalificirane (Ross, 2008). I premda su u posljednjem desetljeću, zbog djelovanja operaističke škole, analizirane mogućnosti solidarnosti između ovih različitih prekarnih pozicija, u tome treba biti oprezan upravo radi objektivnih različitosti kao i subjektivnih procjena pozicija (Gill i Pratt, 2008: 21).

${ }^{14}$ Iz Beckovih teza možemo iščitati Gorzovu analizu o smrti karijere i nastanku radnika/ ce s portfeljem, tj. radnika/ce kao »individualnog poduzeća« (v. Kalanj, 2004: 134).

15 Koncept prekarnosti zapravo ima kršćansko ishodište (detaljnije o prekarnosti v. u: Hromadžić, 2008: 37-38). Za koncept prekarnosti zaslužna je pozicija autonomističkog marksizma kroz uvođenje koncepta precarité. U engleskoj tradiciji je uobičajniji izraz precariousness, ali zbog ulaska termina iz Francuske, uvriježila se novokovanica precarity (Hesmondhalgh i Baker, 2011: 161). 
Može se reći da nesigurnost dominira u svim sferama života i rada pa tako sada nestaje i minimum zaštite koji je država osiguravala radnicima/ ama. U suvremenome neoliberalnom kapitalizmu koji prelazi granice te iznalazi načine da zaobiđe dogovorenu zakonsku regulativu, pod izlikom gospodarskog rasta, traži se da sama država odustane od "neprofitabilne« zaštite rada. Pritom se kao važnije vrednuju investicije nego posljedice koje će one imati na kvalitetu života građana: »Ne uviđa se činjenica da se pod zastavom globalizacije na kocku ne stavljaju samo sindikati, već i politika i država. Političari različitih stranaka, iznenađeni i fascinirani tim 'omekšivačima institucija', tek maglovito počinju naslućivati da se, kao što je to opisao stari Marx, pretvaraju u vlastite 'grobare'" (Beck, 2003: 10). Tako nestabilnost te nužnost promjene ekonomskih i društvenih sustava koju ona za sobom povlači u suvremenom globaliziranom svijetu postaje evidentnom.

Primjetno je da se posljednjih nekoliko godina samoj temi nesigurnosti rada/zaposlenosti poklanja sve više pozornosti, iako je nesigurnosti u radu bilo i prije, pogotovo kad govorimo o »radničkoj klasi«. Sada kad je riječ o (ne)sigurnosti »menadžerske klase«, zatim tzv. »kreativne klase« (Florida, 2002, 2007) i njima analognih tipova, onda ova tema postaje »vruća«. Giddens tako tvrdi da je nesigurnost koju imaju menadžeri/ce i sl. ipak manja nego u drugim manje kvalificiranim skupinama (kao što je pokazala Lilley i dr., 1996, prema Giddens, 2007: 412). Dakle, može se reći da je prekarnost postala postulatom rada u suvremenome kapitalističkom društvu, koje tako obavlja određenu kontrolu, kao što ističe Ross (2008: 44), gdje možemo govoriti o prekarnosti i u slučaju visokokvalificiranih i nižekvalificiranih radnih pozicija. Riječ je o različitim razinama nesigurnosti ovisno o radnim kvalifikacijama, tj. ona se smanjuje s porastom kvalifikacija (Giddens, 2007: 412). S obzirom na to da u oba slučaja govorimo o nestandardnim oblicima rada/zaposlenosti te samim time nesigurnosti zaposlenja, opće fleksibilnosti itd., trebamo biti oprezni jer je riječ o različitim razinama i kontekstima tzv. prekarnosti. Također, može se govoriti o eurocentrizmu i androcentrizmu u analizi rada. Bolje reći, o prekarnosti radnih pozicija počelo se raspravljati tek kad je postao ugrožen »zapadni muški radnik« (Fantone, prema Gill i Pratt, 2008: 11), iako su dotad nesigurne radne pozicije žena, kao i drugih prekarno zaposlenih, bile zanemarivane diljem svijeta.

Iako podaci istraživanja Hesmondhalgha i Baker (2011) podupiru teze autonomista/ica i kritičkih sociologa/inja o prekarnosti i nesigurnosti u 
suvremenom kreativnom radu, oni isto tako zaključuju da općenitost ovih koncepata ne uspijeva zahvatiti specifičnost simboličke naravi kulturnih proizvoda i dinamiku moći kulturnih industrija kao institucija simboličke proizvodnje. Brojne su kontradikcije između umjetničke kreativnosti i zahtjeva tržišta koje su karakteristične za rad u kulturnim i kreativnim industrijama, a koje su upisane u određene organizacijske kontekste. U pokušaju da ostvare autonomiju i samorealizaciju, kulturni se radnici/e moraju boriti s vanjskim i unutarnjim »kontrolnim mehanizmima« koji ograničavaju autonomiju i pridonose samoizrabljivanju (Hesmondhalgh i Baker, 2011). Može se reći da, kako navode prethodni autori, iako je nesigurnost postala postulatom radnog života kao takvog, ona je izraženija u kulturnim i kreativnim industrijama upravo zbog naravi kratkoročnih ugovora dominantnih za taj sektor, kao i vrlo visokoga subjektivnog ulaganja u posao od strane radnika/ca.

\section{Zaključne napomene}

U kulturnim i kreativnim industrijama primjetno je da se rad i radni procesi individualiziraju i fleksibiliziraju. Razvijaju se različiti oblici rada i zaposlenosti kao što su rad od kuće, povremeni rad, samozapošljavanje, radna snaga točno na vrijeme i sl. Pritom je vidljiv i utjecaj novih informacijskih i komunikacijskih tehnologija koje djeluju na sve dimenzije rada: radni procesi i radni stilovi se fleksibiliziraju, a pojavljuju se i nove opcije $\mathrm{i}$ mogućnosti zajedničkog rada, crowdsourcinga ali i participacije korisnika/ ca i nastanak participacijske ekonomije. Od strogosti radnih uvjeta u kojima su djelovali tzv. »plavi ovratnici« pomaknuli smo se prema poslovima u kulturnim i kreativnim industrijama u kojima, kako to kaže Ross (2004), radi neformalnih uvjeta ovratnici nisu potrebni. Fleksibilizira se radno vrijeme i raspored, kao i radni procesi; radno mjesto se u nekim slučajevima doslovce gubi, a radna prava i obveze se redefiniraju. Tako navedene oblike rada i zaposlenosti u kulturnim i kreativnim industrijama možemo najvećim dijelom definirati kao nestandardni oblik (plaćenog) rada/zaposlenosti (Edgell, 2006). Štoviše, taj rad uključuje i podzapošljavanje, ali i neke oblike neplaćenog rada, kao što je volonterski rad.

Promjene u sferi rada i zapošljavanja su u tranziciji od klasično industrijskog rada/zaposlenosti prema postindustrijskim tipovima organizacije rada. Nestandardni oblici rada su sve dominantniji te se u tome smislu u kreativnoj ekonomiji najčešće govori o »atipičnim oblicima zaposlenja« 
(koji su najčešće nepovoljniji i/ili fleksibilniji, zamjenjiviji, a u konačnici - nesigurni). Štoviše, istraživanja pokazuju kako »atipični uvjeti rada« u kojima stvaraju žene (koji su također češće nepovoljniji, fleksibilniji, zamjenjiviji), isto tako postaju karakteristični i za ostale radne skupine. Tendencija je, dakle, prema preobrazbi »atipičnih« (pri čemu najčešće to prelazi u značenje »nepovoljniji«) uvjeta rada $u$ »tipične«, dakle, pri čemu nestandardni oblik rada i zaposlenosti postaje novi standard. U kulturnim i kreativnim industrijama ova »atipičnost« je vezana uz drukčiju narav kulturnog i kreativnog rada koja je pod utjecajem vanjskih i unutarnjih »kontrolnih mehanizama«; kontradikcije koje se pojavljuju zbog želje za autonomijom i samorealizacijom $\mathrm{s}$ jedne, te tržišnih utjecaja s druge strane mogu, zbog visokoga subjektivnog ulaganja, dovesti i do samoizrabljivanja. Govori se o prekarnosti (kulturnih) radnika/ca, međutim, u ovom kontekstu koncept prekarnosti ne može u potpunosti zahvatiti ove specifičnosti te kontradikcije koje proizlaze iz simboličke naravi kulturnih proizvoda te dinamike moći kulturnih i kreativnih industrija kao institucija simboličke proizvodnje. Upravo zbog kompleksnosti i ambivalentnosti rada u kulturnim i kreativnim industrijama potrebna su detaljnija istraživanja ove problematike.

\section{LITERATURA}

Adamović, Mirjana (2011). Žene i društvena moć. Zagreb: Plejada i Institut za društvena istraživanja u Zagrebu.

Anderson, Chris (2006). The Long Tail: How Endless Choice is Creating Unlimited Demand. London: Random House.

Banks, Mark (2007). The Politics of Cultural Work. New York: Palgrave Macmillan.

Barada, Valerija (2012). Žensko iskustvo rada u kreativnim industrijama - primjer dizajnerica vizualnih komunikacija u Hrvatskoj. Doktorska disertacija. Zagreb: Filozofski fakultet Sveučilišta u Zagrebu.

Beck, Ulrich (2001 [1993]). Pronalaženje političkoga: prilog teoriji refleksivne modernizacije. Zagreb: Naklada Jesenski i Turk.

Beck, Ulrich (2003 [1997]). Što je globalizacija? Zablude globalizma - odgovori na globalizaciju. Zagreb: Vizura.

Benkler, Yochai (2006). The Wealth of Networks: How Social Production Transforms Markets and Freedom. New Haven i London: Yale University Press.

Castells, Manuel (2000 [1996]). Uspon umreženog društva. Zagreb: Golden marketing.

Caves, Richard E. (2000). Creative Industries: Contracts between Art and Commerce. Cambridge, Mass.: Harvard University Press. 
Coleman, Gabriella (2005). »The Social Construction of Freedom in Free and Open Source Software: Hackers, Ethics and the Liberal Tradition« (Dissertation Abstract), Chicago: University of Chicago, Department of Anthropology.

Commonwealth Department of Communications and the Arts (1994). Creative Nation: Commonwealth Cultural Policy. Canberra: Department of Communications and the Arts (Australia).

Cvjetičanin, Biserka i Katunarić, Vjeran (ur.). (1998). Kulturna politika Republike Hrvatske: nacionalni izvještaj. Zagreb: Ministarstvo kulture Republike Hrvatske.

DCMS (1998). Creative Industries Mapping Document. London: DCMS.

DCMS (2003). »Creative Industries Fact File«, DCMS-Department for Culture, Media and Sport, Creative Industries Division, http://www.culture.gov.uk/PDF/ ci_fact_file.pdf (25. 09. 2006.).

Edgell, Stephen (2006). The Sociology of Work: Continuity and Change in Paid and Unpaid Work. London: Sage Publications.

ERICarts (2005). Culture-Biz: Locating Women as Film and Book Publishing Professionals in Europe. Bonn: ARCult Media.

EUROSTAT (2004). »Cultural Employment Represents 2.5\% of Total EU Employment«, STAT/04/68, 26 May 2004, http://europa.eu/rapid/pressReleasesAction. do? reference $=$ STAT/04/68\&format=HTML\& (21. 07. 2006.).

EUROSTAT (2011). Cultural Statistics. 2011 Edition. Luxembourg: Publications Office of the European Union. http://epp.eurostat.ec.europa.eu/cache/ITY_OFFPUB/KS-32-10-374/EN/KS-32-10-374-EN.PDF (30. 03. 2012.). doi:10.2785/53528

Flew, Terry (2005). »Creative Economy«, u: John Hartley (ur.). Creative Industries. Malden, Mass.: Blackwell Publishing, str. 344-360.

Florida, Richard (2002). The Rise of the Creative Class: And How It's Transforming Work, Leisure, Community and Everyday Life. New York: Basic Books.

Florida, Richard (2007). The Flight of the Creative Class: The New Global Competition for Talent. New York: HarperCollins.

Giddens, Anthony (2007). Sociologija. Zagreb: Nakladni zavod Globus.

Gill, Rosalind i Pratt, Andy (2008). »In the Social Factory? Immaterial Labour, Precariousness and Cultural Work«, Theory, Culture \& Society, 25 (7-8): 1-30. doi:10.1177/0263276408097794

Hesmondhalgh, David (2002). The Cultural Industries. London: Sage Publications.

Hesmondhalgh, David (2007). „Creative Labour as a Basis for a Critique of Creative Industries Policy«, u: Geert Lovink i Ned Rossiter (ur.). My Creativity Reader: A Critique of Creative Industries. Amsterdam: Institute for Network Cultures, str. 61-69.

Hesmondhalgh, David i Baker, Sarah (2011). Creative Labour: Media Work in Three Cultural Industries. London: Routledge.

Howkins, John (2003). Kreativna ekonomija: kako ljudi zarađuju na idejama. Zagreb: Binoza.

Hromadžić, Hajrudin (2008). Konzumerizam: potreba, životni stil, ideologija. Zagreb: Naklada Jesenski i Turk.

Hui, Desmond (ur.) (2003). Baseline Study on Hong Kong's Creative Industries. Hong Kong: The Central Policy Unit. http:/www.cpu.gov.hk/english/documents/new/press/baseline\%20study\%28eng\%29.pdf. 
IDRC (2007). Open Business Models. Latin America, Final Report. Rio de Janeiro: International Development Research Centre. https://idl-bnc.idrc.ca/dspace/ handle/123456789/34579 (14. 01. 2008.).

Jenkins, Henry (2006). Convergence Culture: Where Old and New Media Collide. New York: New York University Press.

Jovičić, Svetlana i Mikić, Hristina (2006). Creative Industries in Serbia - Basic Facts and Recommendations. Belgrade: British Council.

Kalanj, Rade (2004). Globalizacija i postmodernost: ogledi o misliocima globalne kompleksnosti. Zagreb: Politička kultura.

Katunarić, Vjeran i Cvjetičanin Biserka (ur.) (2003). Hrvatska u 21. stoljeću: strategija kulturnog razvitka. Dokument. Zagreb: Ministarstvo kulture Republike Hrvatske.

KEA (2006). The Economy of Culture in Europe. [Brussels]: KEA European Affairs.

Kodrnja, Jasenka (2001). Nimfe, muze, eurinome: društveni položaj umjetnica u Hrvatskoj. Zagreb: Alinea.

Landry, Charles (2000). The Creative City: A Toolkit for Urban Innovators. London: Earthscan Publications.

Lessig, Lawrence (2004). Free Culture: How Big Media Uses Technology and the Law to Lock Down Culture and Control Creativity. New York: Penguin Press.

Lovink, Geert i Rossiter, Ned (ur.) (2007). My Creativity Reader: A Critique of Creative Industries. Amsterdam: Institute for Network Cultures.

Mayerhofer, Elisabeth i Mokre, Monika (2007). »The Creative Industries in Austria: The Glories of the Past vs. the Uncertainties of the Present«, u: Geert Lovink i Ned Rossiter (ur.). My Creativity Reader: A Critique of Creative Industries. Amsterdam: Institute for Network Cultures, str. 143-152.

McRobbie, Angela (2002). »From Holloway to Hollywood: Happiness at Work in the New Cultural Economy?«, u: Paul du Gay i Michael Pryke (ur.). Cultural Economy: Cultural Analysis and Commercial Life. London: Sage Publications, str. $97-114$.

Milohnić, Aldo (2005). „On 'Flexible' Employment in Culture«, u: Nada ŠvobĐokić (ur.). The Emerging Creative Industries in Southeastern Europe. Zagreb: Institute for International Relations, str. 57-64.

Ministerio de Cultura de Colombia i Convenio Andrés Bello (2003). Impacto económico de las industrias culturales en Colombia. Bogota: Ministerio de Cultura de Colombia i Convenio Andrés Bello. http:/www.odai.org/images/ documentos/impacto $\% 20$ econ $\%$ F3mico $\% 20$ de $\% 201$ as $\% 20$ industrias $\% 20$ culturales $\% 20-\% 20$ colombia.pdf.

MKW (2001). Exploitation and Development of the Job Potential in the Cultural Sector in the Age of Digitalisation. Final Report-Summary. Commissioned by European Commission, DG Employment and Social Affairs. http:/ec.europa. eu/culture/pdf/doc924_en.pdf (29. 07. 2006.).

Neilson, Brett i Rossiter, Ned (2008). »Precarity as a Political Concept, or, Fordism as Exception«, Theory, Culture \& Society, 25 (7-8): 51-72. doi:10.1177/0263276408097796 
O'Connor, Justin (2010). The Cultural and Creative Industries: A Literature Review. 2nd ed. Newcastle upon Tyne: Creativity, Culture and Education (CCE).

Pratt, Andy C. (2004). »The Cultural Economy: A Call for Spatialized 'Production of Culture' Perspectives«, International Journal of Cultural Studies, 7 (1): 117-128. doi:10.1177/1367877904040609

Primorac, Jaka [2008]. The Position of Cultural Workers in Creative Industries. The South-eastern European Perspective. Amsterdam: European Cultural Foundation. http://www.eurocult.org/uploads/docs/902.pdf (28. 09. 2008.).

Radcliffe, Sarah (ur.) (2006). Culture and Development in a Globalizing World: Geographies, Actors and Paradigms. Oxford: Routledge.

Ratzenböck, Veronika, Demel, Katharina, Harauer, Robert, Landsteiner, Günther, Falk, Rahel, Leo, Hannes i Schwarz, Gerhard (2004). An Analysis of the Economic Potential of the Creative Industries in Vienna. Vienna: Kulturdokumentation, Wifo and Mediacult. http://www.creativeindustries.at/pdf/englishsummary.pdf (12. 02. 2012.).

Reidl, Sybille, Schiffbänker, Helene i Eichmann, Hubert (2006). »Sustainable Work in Vienna's Creative Industries - Between Independence and Concerns for the Future?«, http://www.fokus.or.at/fileadmin/fokus/user/downloads/acei paper/Reidl\%20\&\%20Schiffbaenker.doc (23. 02. 2006.).

Rifkin, Jeremy (1995). The End of Work: The Decline of the Global Labor Force and the Dawn of the Post-Market Era. New York: Tarcher.

Ross, Andrew (2004). No-Collar: The Humane Workplace and Its Hidden Costs. Philadelphia: Temple University Press.

Ross, Andrew (2007). »Nice Work if You Can Get It: The Mercurial Career of Creative Industries Policy«, u: Geert Lovink i Ned Rossiter (ur.). My Creativity Reader: A Critique of Creative Industries. Amsterdam: Institute for Network Cultures, str. 19-41.

Ross, Andrew (2008). »The New Geography of Work: Power to the Precarious?«, Theory, Culture \& Society, 25 (7-8): 31-49. doi:10.1177/0263276408097795

Sassen, Saskia (2002). »Towards a Sociology of Information Technology«, Current Sociology, 50 (3): 365-388. doi:10.1177/0011392102050003005

Scott, Allen J. (1999). »The Cultural Economy: Geography and the Creative Field«, Media, Culture \& Society, 21 (6): 807-817. doi:10.1177/016344399021006006

Sennett, Richard (1998). The Corrosion of Character: The Personal Consequences of Work in the New Capitalism. New York: Norton.

Švob-Đokić, Nada, Primorac, Jaka i Jurlin, Krešimir (2008). Kultura zaborava: industrijalizacija kulturnih djelatnosti. Zagreb: Naklada Jesenski i Turk i Hrvatsko sociološko društvo.

Throsby, David (1992). »Artists as Workers«, u: Ruth Towse i Abdul Khakee (ur.). Cultural Economics. Berlin i Heidelberg: Springer-Verlag, str. 201-208.

Throsby, David (2003). »The Cultural Workforce: Issues of Definition and Measurement«, u: Actes du Colloque international sur les statistiques culturelles, Montréal, du 21 au 23 octobre 2002 / Proceedings of the International Symposium on Culture Statistics, Montréal, 21 to 23 October 2002. Québec: Institut 
de la statistique du Québec; Montréal: Institut de statistique de l'UNESCO, str. $173-187$.

Tomić-Koludrović, Inga i Petrić, Mirko (2005). »Creative Industries in Transition: Towards a Creative Economy«, u: Nada Švob-Đokić (ur.). The Emerging Creative Industries in Southeastern Europe. Zagreb: Institute for International Relations, str. 7-23.

Towse, Ruth (2003). »Copyright and Cultural Policy for the Creative Industries« u: Ove Granstrand (ur.). Economics, Law and Intellectual Property: Seeking Strategies for Research and Teaching in a Developing Field. Boston, Mass. i London: Kluwer Academic Publishers, str. 419-438.

UNDP/UNCTAD (2008). Creative Economy Report 2008. The Challenges of Assessing the Creative Economy: Towards Informed Policy-making. http://www. unctad.org/en/docs/ditc20082cer_en.pdf (12. 02. 2009.).

UNDP/UNCTAD (2010). Creative Economy Report 2010. Creative Economy: A Feasible Development Option. http://www.unctad.org/en/docs/ditctab20103 en.pdf (13. 12. 2011.).

UNDP/UNIFEM (2004). Bridging the Gender Digital Divide. A Report on Gender and ICT in Central and Eastern Europe and the Commonwealth of Independent States. Bratislava: UNDP/UNIFEM. http://europeandcis.undp.org/gender/ show/64228D8F-F203-1EE9-B41E082A0C5C1EC1 (12. 03. 2008).

Virno, Paolo (2002). »Multitude and Working Class« (Maurizio Lazzarato interviews Paolo Virno), Multitudes, 9, http://www.generation-online.org/t/multitudeworkingclass.htm (01. 03. 2011.).

Virno, Paolo (2004). Gramatika mnoštva: prilog analizi suvremenih formi života. Zagreb: Naklada Jesenski i Turk.

\title{
From Insecurity to Insecurity: Work and Employment in Cultural and Creative Industries
}

\author{
Jaka PRIMORAC \\ Institute for International Relations, Zagreb, Croatia \\ jaka@irmo.hr
}

The article analyses key aspects of work and employment in cultural and creative
industries. After giving an overview of the specificities of cultural and creative
industries that are important for the development of work and employment, the
article analyses the influence of information and communication technologies
on the latter, and outlines the emergence of participatory models of work and
co-operation. The article proceeds to examine the division of cultural workers
and overviews the types of employment in cultural and creative industries where
atypical employment is highlighted as dominant. Cultural workers encounter in-
equalities that are related to gender, class, age and ethnicity. Special emphasis 
is given to the issues of gender inequality in work and employment in European cultural and creative industries. Insecurity of work and employment in that field is analyzed through the concept of precarity that is becoming more dominant in the explications of contemporary changes in such work. The article shows that the concept of precarity cannot contain all the specificities of symbolical nature in cultural products and the dynamism of cultural and creative industries as institutions of symbolic production. In conclusion, it is shown that further detailed research is needed in order to outline the contradictions of work in cultural and creative industries and to identify all the aspects of its complexity.

Key words: cultural industries, creative industries, creative economy, work, employment, information and communication technologies, cultural worker 